\title{
Congenital megalourethra
}

\author{
Sumit Pruthi • Marguerite T. Parisi
}

Received: 30 January 2009 /Revised: 15 April 2009 /Accepted: 11 May 2009/Published online: 25 June 2009

(C) Springer-Verlag 2009

\begin{abstract}
A 3-day-old boy with an antenatal diagnosis of hydronephrosis and a cyst at the tip of the penis was referred for imaging evaluation. At birth, he exhibited an enlarged phallus and cryptorchidism, and was in renal failure. Renal US demonstrated bilateral renal dysplasia. Voiding cystourethrogram (VCUG) revealed severe vesicoureteral reflux into the ureters with mild dilatation of the pelvicaliceal system, a nontrabeculated bladder (Fig. 1), and an elongated urethra with focal ventral dilatation (Fig. 2, arrow), corresponding to the penile cyst identified prenatally. Radiologic diagnosis of scaphoid megalourethra without posterior urethral valves was con-
\end{abstract}

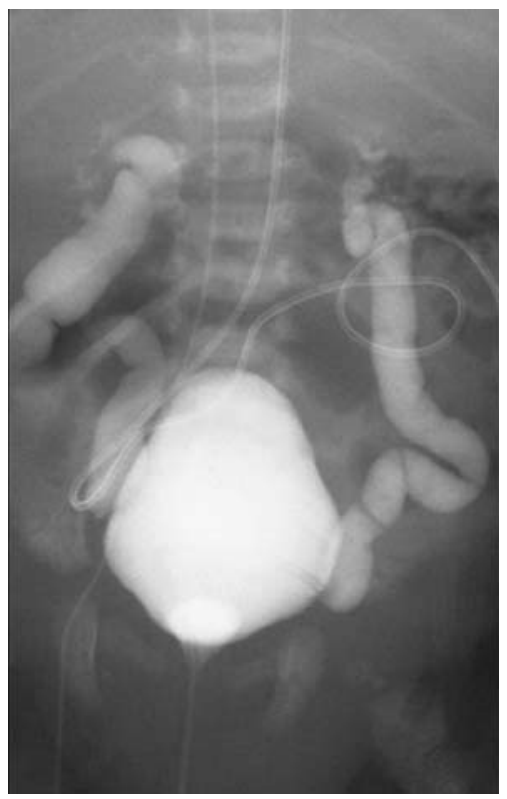

Fig. 1 VCUG with severe reflux

\section{S. Pruthi $\cdot$ M. T. Parisi}

Department of Radiology,

Seattle Children's Hospital and University

of Washington School of Medicine, Seattle, WA, USA

\section{S. Pruthi $(\bowtie)$}

Department of Radiology, R-5417, Seattle Children's Hospital, 4800 Sand Point Way, NE, Seattle, WA 98105, USA

e-mail: sumitp@u.washington.edu

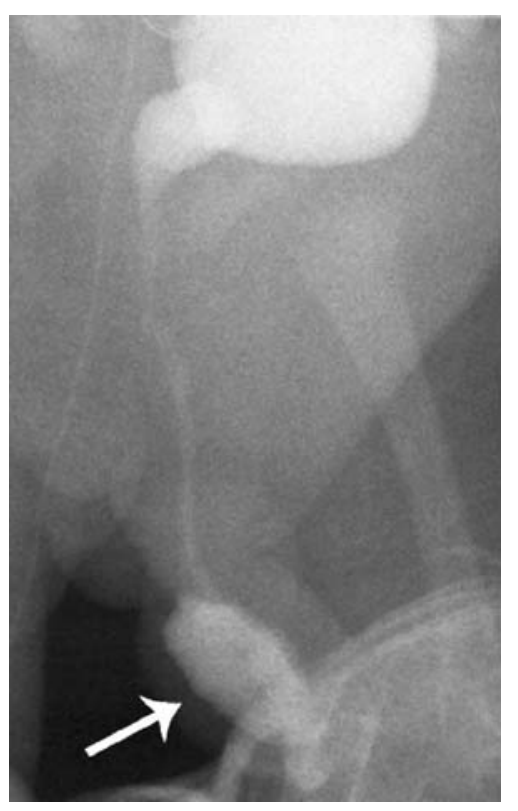

Fig. 2 Elongated urethra with focal ventral dilatation

firmed on cystourethroscopy. Although initially suspected, the child did not have prune belly syndrome.

Classified as either scaphoid/focal or fusiform/diffuse types, megalourethra is characterized by dilatation of the urethra without distal obstruction $[1,2]$. Resulting from a developmental mesodermal defect, patients with megalourethra have absence of the corpora cavernosa and spongiosum with varying degrees of voiding and erectile dysfunction.

Megalourethra is almost universally associated with other malformations (urogenital anomalies, prune belly syndrome, and VATER association) and when diagnosed, radiologic evaluation for other anomalies is mandatory.

\section{References}

1. Jones EA, Freedman AL, Erlich RM (2002) Megalourethra and urethral diverticula. Urol Clin North Am 29:341-348

2. Bates DG (2008) The bladder and urethra. In: Slovis TL (ed) Caffey's pediatric diagnostic imaging, 11th edn. Mosby Elsevier, Philadelphia, pp 2385-2387 